\title{
Learning from the early adopters: developing the digital practitioner
}

\author{
Liz Bennett* \\ School of Education and Professional Development, University of Huddersfield, \\ Huddersfield, UK
}

(Received 16 May 2013; final version received 18 March 2014)

\begin{abstract}
This paper explores how Sharpe and Beetham's Digital Literacies Framework which was derived to model students' digital literacies, can be applied to lecturers' digital literacy practices. Data from a small-scale phenomenological study of higher education lecturers who used Web 2.0 in their teaching and learning practices are used to examine if this pyramid model represents their motivations for adopting technology-enhanced learning in their pedagogic practices. The paper argues that whilst Sharpe and Beetham's model has utility in many regards, these lecturers were mainly motivated by the desire to achieve their pedagogic goals rather than by a desire to become a digital practitioner.
\end{abstract}

Keywords: pedagogic goal; belief; digital practitioner; motivation; framework; model

\section{Introduction}

This paper explores the developing practices that surround the adoption of Web 2.0 tools in higher education teaching and learning. Web 2.0 tools and services enable participation and collaboration at scale over the web and facilitate new forms of knowledge generation and participation in knowledge-building communities. Indeed many authors have commented on the potential of the web to challenge traditional academic ways of knowing (Beetham, McGill, and Littlejohn 2009; Crook 2008; Dohn 2009; Land and Bayne 2008). However, this new academic paradigm requires new skills and practices which Beetham and Sharpe (2011) define as digital literacies:

The functional access, skills and practices necessary to become a confident, agile adopter of a range of technologies for personal, academic and professional use.

The discussion of digital tools and how they are being incorporated into educational practices has tended to focus on students' needs and development. Yet as Lea and Jones (2011) noted, it is the institution that validates particular aspects of digital literacy practices and it is lecturers who design and deliver the curriculum thus shaping how technologies are embedded into students' learning experiences. Indeed the UK Committee of Inquiry into the Changing Learner Experience (CLEX) identified staff skills in using Web 2.0 tools as a 'critical issue' for the sector (CLEX 2009, p. 7).

\footnotetext{
*Email: e.bennett@hud.ac.uk

Research in Learning Technology 2014. (C) 2014 L. Bennett. Research in Learning Technology is the journal of the Association for Learning Technology (ALT), a UK-based professional and scholarly society and membership organisation. ALT is registered charity number 1063519 . http://www.alt.ac.uk/. This is an Open Access article distributed under the terms of the Creative Commons CC-BY 4.0 License (http:// creativecommons.org/licenses/by/4.0/), allowing third parties to copy and redistribute the material in any medium or format and to remix, transform, and build upon the material for any purpose, even commercially, provided the original work is properly cited and states its license. 


\section{Bennett}

This paper explores how a small group of lecturers experienced the challenges and opportunities of using Web 2.0 tools and services in their pedagogical practices and in particular it focusses on their digital competency and their motivations to adopt technology-enhanced learning (TEL) practices. The discussion is structured around Sharpe and Beetham's (2010) model of students' digital literacies which is critically examined and applied to the development of lecturers' digital pedagogical practices.

\section{Digital literacies: digital practices}

Friesen, Gourlay, and Oliver (2014) argue for the importance of developing an empirically grounded, theoretically informed discussion in order to explore how learning behaviours have been changed through the use of online tools and services. There are a number of models of students' digital literacies (e.g. Belshaw 2011; $\mathrm{Ng}$ 2012). One such framework is Sharpe and Beetham's (2010) Figure 1. It has particular value because rather than focussing on different types of digital literacies (e.g. finding sources, critically evaluating sources, applying sources to new contexts) the model distinguishes between access, skills, practices and attributes and articulates how they relate in a hierarchy. The model was inspired by Maslow's (1943) hierarchy of needs and both have lower levels that are fundamental elements, whilst the top levels represent more enduring aspects of identity. Sharpe and Beetham's model depicts the motivation for developing students' digital literacy and locates digital literacies as social practices. The model has limitations in that it treats learners as individuals and does not depict the social relations, any cultural dimension or the ideological and political frameworks that shape the learner's experience but has become popular perhaps due to is simplicity and because it moves beyond a tick box approach to digital literacies (Gourlay, Hamilton, and Lea 2014).

Figure 1 shows Sharpe and Beetham's (2010) model. Access at the bottom layer of the pyramid represents the most fundamental conditions necessary for learners to engage in using technology to support their learning and includes availability of appropriate hardware, connection to the Internet and being able to access web-based tools or the institutional VLE, etc. Sharpe and Beetham (2010) also suggest that the issues surrounding time and its management are aspects of the access level. The second level of the framework represents the skills which students draw on in the application of technology to learning. These include skills in information literacy, meta,cognitive, ICT skills (handling different types of information sources and media), being able to interact effectively with social and professional groups etc. (Sharpe and Beetham 2010). Practices are defined as 'Learners mak[ing] informed

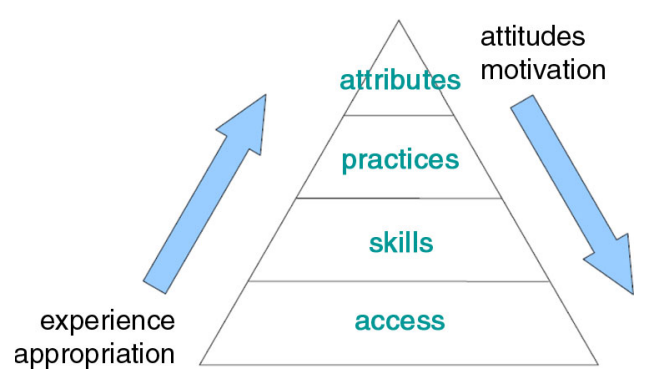

Figure 1. Beetham and Sharpe's (2011) model of students' digital literacies. 
choices about how to use technologies, alone and with others. They develop personal, flexible strategies in response to situational needs' (Beetham and Sharpe 2011). Hence these practices are localised in that they relate to a particular discipline context. For instance, in a health context they might include maintaining a patient record system whereas in engineering they could include using modelling software to achieve produce a real-time simulation of the behaviour of a particular equipment behaviour. At the top level, attributes relate to a student's attitude and identity in relation to their learning. Beetham and Sharpe (2011) suggest that a learner who operates at this level of the pyramid has a strongly developed understanding of the value and possibilities of using technology to support their learning. This includes six attributes identified by Sharpe (2014); being engaged, connected, confident, adaptable, intentional and self-aware.

The left hand upward arrow in Figure 1 shows how access can drive development of skills, which can in turn result in effective practices and identification with the attributes of a confident digital learner. Likewise, the right hand downward arrow illustrates how a student's attitude towards technology provides motivation to learn new practices and to develop new skills and acquire access.

\section{Methodology}

This paper set out to explore the way that lecturers make use of digital tools in their pedagogical practice. It is based on the findings of a phenomenological small-scale study into the experiences of lecturers in one university in England as they adopt Web 2.0 tools in their teaching and learning practices. Phenomenology is a methodology that aims to understand a topic through the experiences of the participants and to value the uniqueness of these experiences. Titchen and Hobson (2011) outline two approaches to phenomenology; direct and indirect. In this study a direct approach was taken which involved discussion of participants' approaches to using of technology in their teaching, their motivations for adoption, and the successes and challenges that they encountered.

A purposive sample was constructed of 16 lecturers (11 women and 5 men) with responsibility for delivery of a syllabus and its assessment. The sample included those who were trying out TEL cautiously and sceptically alongside the enthusiastic innovators; the 'innovators' and 'early adopters' in Rogers' (1983) terminology related to the diffusion of innovation in social organisations. They were drawn from across the university covering both pure and applied subjects both in the hard and soft subjects (Lindblom-Ylanne, Trigwell, and Ashwin 2006). Lecturers with experience of using Web 2.0 tools were sought; 12 of the sample had six or more years' experience but the remaining four were new to using Web 2.0 tools. The majority used TEL within a blended delivery with some face-to-face elements, although some taught wholly online. A range of tools was used including institutionally supported products such as the VLE's wiki, blog and discussion boards and other tools including Facebook, Twitter, Mahara.

Interviews generally lasted between 1 hour and 90 minutes and provided opportunity for in-depth discussion. I aimed to build rapport with the participants and to position myself as someone who is also engaged in similar teaching and learning developments. Indeed personal relationships between the researcher and the interviewees enhanced the data collection process through the intimate nature of the interview, underpinned by principles of anonymity and approaching it as an empathic 


\section{Bennett}

exchange (Clegg et al. 2006). BERA's (2011) ethical guidelines were applied (e.g. informed consent, right to withdraw from the research). Pseudonyms have been used in reporting the data to ensure participants' anonymity.

Interviews were taped, transcribed and analysed using template analysis (King 2004). The aim of the analysis was to explore the extent to which a model derived from students' engagement with digital literacies could be applied to lecturers. The topic lent itself to a phenomenological approach which enabled the richness of the data to be explored (Friesen 2008). Similarly Trowler and Cooper (2002) note practices are highly contextualised so the small-scale format gave opportunities to explore the complexity of these interrelated factors. Mechanisms to support reflexive awareness were adopted (for instance awareness of my prior assumptions, on-going reflections and use of a research diary to review my values and beliefs).

\section{Application of Beetham and Sharpe's model to lecturers}

The paper explores the extent to which Sharpe and Beetham's (2010) model can be applied to this study's data derived from lecturers' experiences. The discussion starts with the top level and works down the model's levels illuminating the extent to which there is a fit or dissonance with the data from the early adopters in this study.

\section{Attribute level}

The top level, Figure 1, describes the attributes, the more stable aspects of their personality, which enable lecturers to make use of their skills and practices to design and deliver learning activities which make use of technology. It appeared that lecturers felt connected and committed to ways of working using digital tools. They gravitated to these ways of working and they are the 'norms' of their practice:

It [teaching with Web 2.0 tools] just feels normal. I don't think I could teach if I went to another institution somewhere else where everything was chalk and talk. I think I'd die a death now because I'm so ingrained with it. [James]

Other lecturers also illustrated how new ways of working are assimilated into their beliefs and ways of operating. Sue said 'I didn't think of not doing' when asked why she had decided to adopt an online tool because she saw it as the normal thing to do. In this way digital practices become normal, rather than exceptional, once they are part of the practitioner's repertoire. This assimilation of practices into a sense of being resonates with Ecclesfield, Rebbeck, and Garnett's (2012) ideas of normalising of digital practices and White and Le Cornu's (2011) notions of Post Digital in that once they become learnt they are part of one's repertoire. Thus, this finding suggests that for many of these early adopters, the assimilation of a practice into one's belief system appears to reflect an orientation towards technology which is notable and different from merely identifying a 'skill set' in that it is embedded into the lecturers' values and beliefs.

\section{Practice level}

Lecturers in this study reported a wealth of expertise in the complexity of online learning and of their role as designers and facilitators of that learning. This included an 
understanding of how to design online learning activities, management of the learning process for both individuals and with groups. But they did so thoughtfully in order to address a pedagogical need rather than focussing on the technology for its own sake:

One thing I am very conscious of is that I don't want to use technology for the sake of what it looks like ... I only use it when I think it benefits them ... I think that is the key to any of this technology is that you should only use it if you can see a clear benefit to the students ... If you put technology in for technology's sake they don't like doing it, but they do like doing it if it serves a purpose. [Rachel]

For Sue and Richard their knowledge of the tools is entwined with what they want to achieve to support students' learning:

They could submit their portfolio via the blog tool. But that seemed quite complicated to get them to do ... the more that you give them [to do] the more complex it gets. [Sue]

I think possibly one of the areas that we haven't focussed so much of is the ability to provide comments on wiki pages which I think is the next level of development where ... there would be an opportunity to challenge misinformation, or not even that, but address things that may need further clarification that students haven't already pulled out. So I'm aware that wikis allow that to happen. [Richard]

The most experienced lecturers appeared to understand the tools and how they could be used within a learning activity. When they discussed designing for learning sometimes it appeared to be a 'dance' whereby the technology's features afforded particular ways of being used which needed to be thoughtful applied to enable them to support learning. Sue discusses the value of portfolios as a learning strategy and the way that a blog can facilitate this balanced against the complexity for her students whilst Richard debates using comments within a wiki to develop his students' critical engagement. Similarly Mishra and Koehler (2006) argue that it is inappropriate to separate technological skills from the way that they impact on both the content knowledge (what is going to be taught) and the pedagogical knowledge (how it is going to be taught).

\section{Skills level}

The 'skills level' in Sharpe and Beetham's (2010) framework focusses on how students develop their technical, information, communication and learning skills. For tutors, the skills they reported were a detailed understanding of how the tools operated, for example, their features, permanence, their stability, knowledge of how simple they were to use and to learn, how robust and reliable one tool was over another, types of video formats and the impact of different formats on delivery times. The quotes from Sue and Richard, in relation to the Practice level, illustrate these skills (alongside how they apply in practice).

Whilst many lecturers in the study demonstrated that they felt adequately technically skilled for their role, it was also evident that, some felt that their skills were not as good as their students, and notably this was not something of concern:

My technological skills [are not as good as my students] yes definitely ... I don't think it matters as long as you build up some collaborative trusting relationship with them. [Catherine] 


\section{Bennett}

Many discussed a variety of techniques for managing limitations in their skills including being open and honest about their role as teachers, developing their skills through exploration and seeking out guidance and through developing their esteem with their students in terms of other aspects of their role:

I think it is important that we have to make our positions clear, that we are not practising designers and technologists on a regular basis. [Adrian]

One colleague was aware of her limited technical skill and found it worrying, not in terms of her self-esteem, but in relation to being able to support her students in handling the technology. In addition, this colleague expressed anxiety related to having, what she feels to be, an incomplete understanding of the technological tool:

I've only got a very superficial surface learning of how this thing works and as an academic you don't feel confident with that superficial learning and I want a deeper learning of how it all works. [Emily]

To summarise, given the sample of early adopters, it is not surprising to find that technical skills were not evident as a consistent concern; however, Emily's view suggests that skills may be an anxiety for those beyond the early adopter group.

The focus in this section has been on technical skills, but lecturers also discussed their online information literacy skills and universally they were happy with their own online information literacy skills.

\section{Access level}

In Sharpe and Beetham's (2010) learner-focussed framework, the access level incorporates students' access to devices, technologies, resources and services. It includes aspects of ownership of devices, the accessibility of the tools, learning and issues related to time and time management. The data from this study showed that lecturers' access to devices and to the online world did not appear to concern them. There was an assumption that access to devices connected to the Internet was there when they needed it. No one commented on the cost of purchasing equipment or of maintaining their Internet connection and one might infer that they did not resent the costs associated with access. However, the issues of time management and the management of the boundary between lecturers' personal and professional lives appeared to be a concern for some tutors. This issue has two aspects: firstly in terms of the amount of time to learn the new tools, and secondly the way that lecturers' personal and professional boundaries could be challenged when using Web 2.0 tools which are 'always on'.

\section{Access level: time and investment in learning new skills}

It was common for learning new skills to be described by lecturers as an investment. They spoke about recognising that there was an investment needed which pays off, either in terms of saving time later, or in terms of improved teaching and learning opportunities for their students. James sums up both succinctly: 
I actually use them because one, I think they work, but two, in a lot of ways they save my time. [James]

\section{Access level: new ways of working}

It was also common that lecturers actively welcomed new ways of working that web tools enable or they accepted them as a necessary aspect of their working lives:

I think it [the use of Web 2 tools] will lead to [blurring of boundaries of home and work] but I've accepted that. [Jennifer]

So there is a bit of boundary erosion due to technology but I find it helps because I can quickly reply ... I can just keep an eye on what's going on. I don't spend too much time [working at home]. I just take a quick look and reply to a student. [Abigail]

Others identified particular strategies that they used to manage those boundaries and the expectations of their students. These included not accepting students as friends in social media and giving students clear guidance in terms of when and what they can expect of them online:

I'm quite boundaried in my use of Web 2 technologies ... You have to set up the expectation around engaging with this technology with the clear message that you as a tutor will be investing this much time in engaging with students' work. [Richard]

Others had developed practical ways of demarking their lives:

I don't use my laptop at home. I do use my iPad but I choose which bits I want to do.

I don't let my work life dictate to me at home ... [Catherine]

However, amongst this overwhelming positive picture of staff investing and managing their time, there were other examples of colleagues who experienced this investment as a challenge in their working lives:

The main obstacle to that is volume of work ... I feel like I haven't got the space to take time out to learn a new skill properly and that is a real, a significant and real hindrance. [Emily]

Thus, the picture is mixed, with some lecturers feeling in control of their lives through their use of technology, and some feeling under some additional pressures. Overall, those who had effective time management strategies were dominant, reflecting perhaps an aspect of the early adopters' attitudes, practices and skills and something different to the experience reported by those who come later and more reluctantly to adoption of online teaching practices (Folley 2013).

\section{The Digital Practitioner Framework}

The data from this small-scale study has illustrated that Beetham and Sharpe's framework can be applied to the data from some early adopters of online teaching practices. Figure 2 provides a revised framework with descriptors which I have called The Digital Practitioner Framework (DPF). It is proposed as a way of modelling the characteristics that are likely to be found in lecturers who adopt technology in 


\section{Bennett}

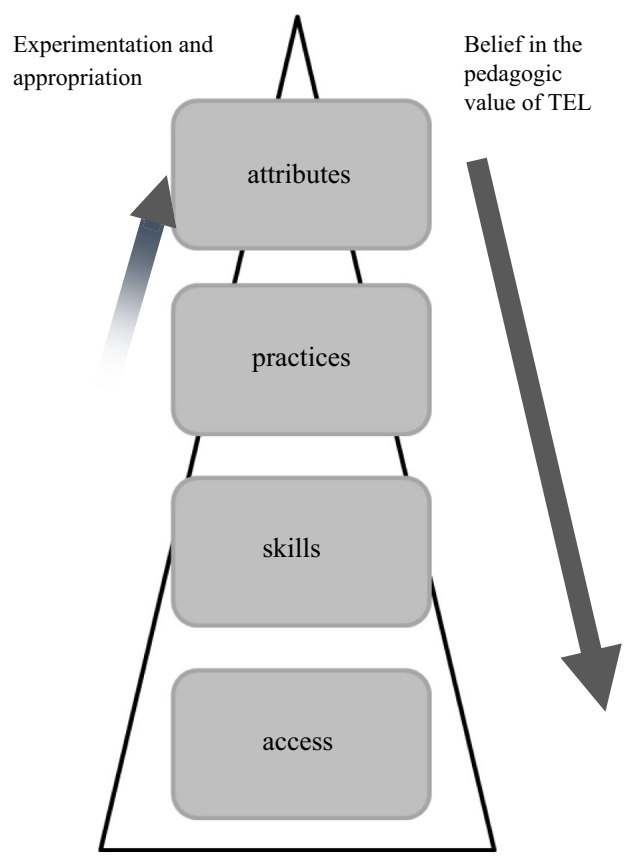

\begin{tabular}{l} 
I am \\
confident in my attitude to TEL; \\
willing to experiment with technology and how it can be \\
used in teaching and learning; \\
able to balance risks of change with its potential; \\
convinced by the potential of technology to enhance and \\
transform learning; \\
willing to invest time in exploring and evaluating TEL. \\
I design learning activities to suit my students' needs \\
using TEL as appropriate. \\
I facilitate learning using appropriate technological \\
tools. \\
I explore the capabilities of technology. \\
I behave ethically in contexts where the digital media is \\
blurring boundaries. \\
I evaluate my practices. \\
I reflect on innovations in my practice. \\
I experiment with tools in my practice. \\
\hline $\begin{array}{l}\text { I can: } \\
\text { use TEL tools to suit my needs; } \\
\text { manage the blurring of boundaries between private and } \\
\text { work time. }\end{array}$ \\
I have access to: \\
networked devices and applications. \\
media devices. \\
people who can support me in using technology. \\
a network of people with ideas for using technology. \\
\end{tabular}

Figure 2. The Digital Practitioner Framework.

their teaching and learning practices. The framework represents the attributes, practices and skills and access of Ecclesfield, Rebbeck, and Garnett's (2012) notion of a 'digital practitioner':

the "digital practitioner" is, in part, the "communicative practitioner" whose focus has become the initiation, support and facilitation of learning and whose expertise resides in both their subject knowledge and their ability to use technology and develop technology use in their students that opens out "ecology of knowledge and learning" and creates contexts to generate "obuchenie" where learning and teaching can become fused in collaboration. (p. 53)

The descriptors represent characteristics which were evident in many of the participants in my study. These descriptors are suggested to illuminate the attitudes, practices, skills and access features of those lecturers who are willingly trying out and experimenting with use of TEL in their pedagogic practice. They are proposed to stimulate further debate about lecturers' dispositions in relation to TEL practices.

\section{Developing the digital practitioner}

Sharpe and Beetham (2010) (Figure 1) have considered how the levels of the pyramid relate to one another. They show an arrow going up the pyramid labelled 'experience and appropriation' to show that students' experience of using tools and applying them in learning contexts drives their sense beliefs and attitudes. Similarly, they suggest that 'attitudes and motivation', that is being a digitally confident learner, motivates students to try out new practices, acquire new skills and to purchase new devices and software and explains movement down the pyramid. The data from tutors were interrogated to see if similar movement and drivers were evident. 


\section{Does identity drive uptake?}

Sharpe and Beetham (2010) suggest that learners' attributes, their sense of identity with and as a digital scholar, motivate them to acquire new practices, to learn new skills and to improve access. Lecturers' identity did affect motivation in some cases. For instance Claudia, expressed her motivation to spend time learning a new tool very directly. Her simple clarity around her motivations gives weight to the notion that one's identity as a confident digital practitioner is a significant motivator for learning new skills and practices:

It [investing time] doesn’t worry me much; I'm quite motivated to do it. [Claudia]

However, the overriding driver for uptake of TEL practices appeared to be the desire to improve to deliver high quality learning for their students:

It [learning to use video] was more through necessity as I recognised that it would be a really good way of doing things. [James]

I just thought this looks really interesting. I didn't think, 'oh, it's going to take [time]'.

[I think] I'm going to make time for it. Like any other thing that I'm impressed with that

is going to be good for the students. [Abigail]

Lecturers' attributes included not just confidence or sense of self-efficacy in relation to use of technology, but also, critically, a belief in its value. Whilst these appeared to affect lecturers' desire to try out new practices, it appeared that the overriding driver was a commitment to serve their students. It has been noted by Masterman and Manton (2011) that beliefs give rise to motivation which is critical to TEL adoption. Likewise, Ertmer and Ottenbreit-Leftwich (2010) argue that self-efficacy and a belief in the value of technology are critical factors to the uptake of TEL practices. It appears that lecturers place great emphasis on meeting the needs and interests of their students, which Jephcote and Salsibury (2009) call the 'principled ethics of care' (p. 971). Similarly Cuban (1998, p. 71) found that teachers used technology when it supported reaching predetermined pedagogical goals and resisted changes that they believed to be irrelevant to their practice.

Hence a key finding of this study is that rather than notions of identity driving uptake instead these lecturers were motivated by their belief in the value of TEL to support improved student learning. This is a point of departure from Sharpe and Beetham's (2010) model in that the emphasis for lecturers is on serving their pedagogic goals rather than self-actualising as digital pedagogues.

This is illustrated in Figure 2, the DPF, by the downward arrow annotated with belief in the pedagogic value of TEL. The arrow covers all four levels to suggest that belief in TEL's pedagogic value drives these lecturers to adopt TEL in their practice, develop skills and to get access.

\section{Does access drive uptake? Movement up the pyramid}

Lecturers in general did not appear to be particularly interested in the technology for its own sake. In many cases they only wanted to use tools when they have a role in supporting their teaching and learning practices. However, they recognised that they need to invest time in order to understand the tools and to assess their potential. They were also aware of the time consuming nature of learning to use new tools and 


\title{
L. Bennett
}

that these skills were not stable and thus subject to frequent updating. This led to diffidence in their approach to developing skills. It was common for lecturers to show a lack of interest in the technology:

But there was nothing that drew me in those early stages that made me think I'm going to gain something through going through this learning curve. [Richard]

What appeared too was that although lecturers were not particularly interested in the technical skills per se, they often needed to understand the tools in quite a detailed way in order to make appropriate use of them in teaching practices:

We tried to use the Blackboard one [wiki] for art and design students particularly ... [but] it was very hard to make it visually strong. They didn't like the fact that it loaded in alphabetical, rather than chronological, order. [Jennifer]

They've got a new version [of a wiki tool] now. It looks very nice but it is a bit more complicated to set up in terms of access for the students, because what I had previously was each team had one user name and password so that was quite easy to organise. [Abigail]

Hence the pattern of skills and experience driving appropriation did not, generally, appear to be evident in the data. Lecturers did not talk about the tools with particular interest or concern, instead they focussed on their potential to support teaching and learning. It has been suggested that it is lecturers' skills that are a significant barrier to uptake of TEL practices (Cooke 2008; Browne et al. 2010). However, the findings from this study illustrate something different, in that skills are not the main barrier to adoption of TEL.

There was evidence of lecturers experimenting and trying out tools in their practice to see how they worked:

\begin{abstract}
Alison suggested that we used that because she'd evaluated it. I was happy to go ahead with that and to take her advice. And that's proved to be true really ... I couldn't be more delighted with what they'd achieved. [Jennifer]

It all started because I went to a lunch time taster session one that John [the Learning Technology Advisor] did that was on wikis. He said at that stage a blog would be better than a wiki. So that was the process of making it a blog. [And it was] successful on lots of levels. [Emily]
\end{abstract}

In these examples, the lecturers' successful experimentation with TEL practices led to developing their confidence and thus their identity as a digital practitioner growing, that is where movement up the pyramid was evident. This is shown by the shorter upwards arrow which starts at the practice level to show that successful adoption of TEL appears to change a lecturer's belief about its value. It was rare that increased access or skills drove adoption of teaching and learning practices and hence the arrow does not begin with at the bottom of the pyramid. This contrasts with the student model (which has its upward arrow starting at the bottom level).

Thus, whilst this study has argued that uptake of TEL practices is driven by a lecturers' belief in the value of technology to enhance learning, there are occasions when trying out a TEL practice as an experiment rather than committed to its value has resulted in lecturers developing as digital practitioners. If their experimental use of TEL was successful then this changed their belief in its value: they became more fully a digital practitioner (Ecclesfield, Rebbeck, and Garnett 2012). 


\section{Conclusions}

This paper has reviewed Sharpe and Beetham's (2010) model of students' digital literacies in light of new evidence from a small-scale study of lecturers in one higher education institution who are making use of learning technologies in their pedagogical practices. As a result a revised form of this model that applies to these lecturers has been developed. This model, the DPF, represents the notion of the 'digital practitioner' as proposed by Ecclesfield, Rebbeck, and Garnett (2012). This notion describes lecturers who are confident in their use of TEL, have a self-managed approach to adoption, willingness to experiment and to invest time in exploring the tools and how they might be applied to teaching and learning practice. The DPF suggests that there are some attributes that these digitally confident practitioners share that build on their access, skills and practices. The model is proposed based on this study's findings but further work is needed to explore how the model applies more widely.

The congruence between Sharpe and Beetham's (2010) model and the DPF suggests that both students' and lecturers' digital literacies can be understood as a hierarchy of access, skills, practices and attributes. However, the DPF departs from Sharpe and Beetham's model in that it suggests, rather than a desire to become a digital practitioner being the motivating factor for adoption of TEL practices, that lecturers are motivated by achieving improved teaching and learning outcomes for their students. The importance of achieving a particular goal, which for lecturers was a pedagogic goal, appears to challenge aspects of Sharpe and Beetham's model of students' digital literacies that warrants further investigation.

\section{Acknowledgements}

I wish to extend my thanks to the reviewers for the detailed and insightful comments, which have helped to improve the paper significantly. I am particularly grateful to Professor Lyn Tett for encouragement and guidance.

\section{References}

Beetham, H., McGill, L. \& Littlejohn, A. (2009) Thriving in the 21st century: Learning Literacies for the Digital Age (LLiDA project) [online], Available at: http://www.academy. gcal.ac.uk/llida/LLiDAReportJune2009.pdf

Beetham, H. \& Sharpe, R. (2011) 'Digital literacies workshop', Paper presented at the JISC Learning Literacies Workshop, Birmingham [online], Available at: http://jiscdesignstudio. pbworks.com/w/page/40474566/JISC Digital Literacy Workshop materials

Belshaw, D. (2011) What is Digital Literacy? A Pragmatic Investigation, Doctorate in Education, University of Durham, Durham.

British Educational Research Association (BERA). (2011) Revised Ethical Guidelines for Educational Research, BERA, Nottingham.

Browne, T., et al., (2010) 2010 Survey of Technology Enhanced Learning for Higher Education in the UK, UCISA [online], Available at: www.ucisa.ac.uk/publications/ /media/groups/tlig/ vle_surveys/TEL $\% 20$ survey $\% 202008 \% 20$ pdf.ashx [Accessed 18 July 2014].

Clegg, S., et al., (2006) 'Self-development in support of innovative pedagogies: peer support using email', International Journal for Academic Development, vol. 11, no. 2, pp. 91-100.

Committee of Inquiry into the Changing Learner Experience (CLEX). (2009) Higher Education in a Web 2.0 World, Committee of Inquiry into the Changing Learner Experience [online], Available at: www.jisc.ac.uk/publications/documents/heweb2.aspx [Accessed 18 July 2014]. 


\section{Bennett}

Cooke, R. (2008) On-line Innovation in Higher Education, DIUS [online], Available at: http://webarchive.nationalarchives.gov.uk/tna/+/http:/www.dius.gov.uk/policy/documents/ online_innovation_in_he_131008.pdf [Accessed 18 July 2014].

Crook, C. (2008) Web 2.0 Technologies for Learning: The Current Landscape - Opportunities, Challenges and Tensions, Becta [online], Available at: http://dera.ioe.ac.uk/1474/1/becta_ 2008_web2_currentlandscape_litrev.pdf [Accessed 18 July 2014].

Cuban, L. (1998) Teachers and Machines: The Classroom Use of Technology Since 1920, Teachers College, New York.

Dohn, N. (2009) 'Web 2.0-mediated competence - implicit educational demands on learners', Electronic Journal of e-Learning, vol. 7, no. 2, pp. 111-118.

Ecclesfield, N., Rebbeck, G. \& Garnett, F. (2012) 'The case of the curious and the confident the untold story of changing teacher attitudes to e-learning and "technology in action" in the FE sector', Compass: The Journal of Learning and Teaching at the University of Greenwich, no. 5, pp. 45-56.

Ertmer, P. \& Ottenbreit-Leftwich, A. (2010) 'Teacher technology change: how knowledge, confidence, beliefs, and culture intersect', Journal of Research on Technology in Education, vol. 42 , no. 3, pp. 255-284.

Folley, S. (2013) Bridging the Gap between Face-to-Face and Online Teaching: A Case Study Exploring Tutors' Early Experiences of Teaching Online in a UK University 2009-2012, Doctoral Thesis, University of Huddersfield.

Friesen, N. (2008) 'Chronicles of change: the narrative turn and e-learning', E-Learning, vol. 5, no. 3, pp. 298-310.

Friesen, N., Gourlay, L. \& Oliver, M. (2014) 'Editorial: scholarship and literacies in a digital age', Research in Learning Technology, vol. 21, 23834. doi: 10.3402/rlt.v21.23834.

Gourlay, L., Hamilton, M. \& Lea, M. (2014) 'Textual practices in the new media digital landscape: messing with digital literacies', Research in Learning Technology, vol. 21, 21438. doi: $10.3402 /$ rlt.v21.21438.

Jephcote, M. \& Salisbury, J. (2009) 'Further education teachers' accounts of their professional identities', Teaching and Teacher Education, vol. 25, no. 7, pp. 966-972. doi: 10.1016/ j.tate.2009.05.010.

King, N. (2004) 'Using interviews', in Essential guide to qualitative methods in organizational research, eds C. Cassell \& G. Symon, Sage, London, pp. 11-22.

Land, R. \& Bayne, S. (2008) 'Social technologies in higher education: authorship, subjectivity and temporality', Paper presented at the Proceedings of the 6th International Conference on Networked Learning, pp. 675-681.

Lea, M. \& Jones, S. (2011) 'Digital literacies in higher education: exploring textual and technological practice', Studies in Higher Education, vol. 36, no. 4, p. 377.

Lindblom-Ylanne, S., et al., (2006) 'How approaches to teaching are affected by discipline and teaching context', Studies in Higher Education, vol. 31, no. 3, pp. 285-298.

Maslow, A. H. (1943) 'A theory of human motivation', Psychological Review, vol. 50, no. 4, pp. 370-396. doi: 10.1037/h0054346.

Masterman, E. \& Manton, M. (2011) 'Teachers' perspectives on digital tools for pedagogic planning and design', Technology, Pedagogy and Education, vol. 20, no. 2, pp. 227-246.

Mishra, P. \& Koehler, M. (2006) 'Technological pedagogical content knowledge: a framework for teacher knowledge', Teachers College Record, vol. 108, no. 6, pp. 1017-1054.

$\mathrm{Ng}$, W. (2012) 'Can we teach digital natives digital literacy?' Computers \& Education, vol. 59, no. 3, pp. 1065-1078. doi: http://dx.doi.org/10.1016/j.compedu.2012.04.016.

Rogers, E. M. (1983) Diffusion of Innovation, 3rd edn, Free Press, London.

Sharpe, R. (2014) 'What's at the top of the pyramid', 24th January 2014 Oxford Brookes University [online], Available at: http://dlf.brookesblogs.net/archives/127 [Accessed 18 July 2014].

Sharpe, R. \& Beetham, H. (2010) 'Understanding students' uses of technology for learning: towards creative appropriation', in Rethinking Learning for the Digital Age: how Learners Shape their Experiences, eds R. Sharpe, H. Beetham \& S. de Freitas, Routledge Falmer, London, pp. 85-99.

Titchen, A. \& Hobson, D. (2011) 'Understanding phenomenology through reverse perspectives', in Theory and Methods in Social Research, 2nd edn, eds B. Somekh \& C. Lewin, Sage, London, pp. 121-128. 
Trowler, P. \& Cooper, A. (2002) 'Teaching and learning regimes: implicit theories and recurrent practices in the enhancement of teaching and learning through educational development programmes', Higher Education Research \& Development, vol. 21, no. 3, pp. 221-240.

White, D. \& Le Cornu, A. (2011) 'Visitors and residents: a new typology for online engagement', First Monday, vol. 16, no. 9. 